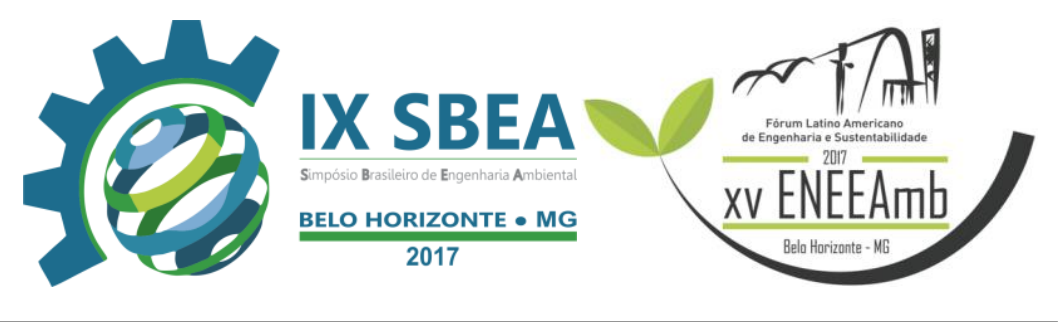

\title{
DIAGNÓSTICO DAS CONDIÇÕES SANITÁRIAS E AMBIENTAIS DE UM MUNICÍPIO DO AGRESTE PARAIBANO
}

Adriano Oliveira da Silva - adriano_able@ hotmail.com

Universidade Estadual da Paraíba-UEPB

Vera Lúcia Meira de Morais Silva - meiravlm@yahoo.com.br

Universidade Estadual da Paraíba-UEPB

Camila Bonfim Miranda - camilabonfimm@gmail.com

Universidade Estadual da Paraíba-UEPB

Isabella Vieira dos Santos- e-mail

Universidade Estadual da Paraíba-UEPB

Thiago Santos de Almeida Lopes - thiago.s.16@ hotmail.com

Universidade Federal da Paraíba-UFPB 


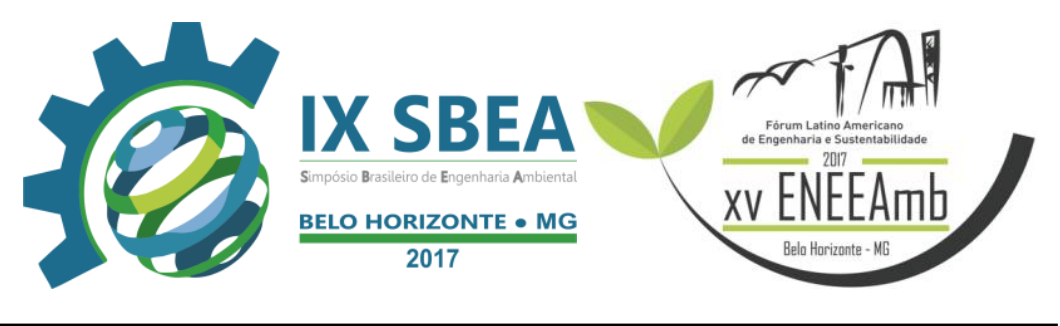

\section{RESUMO}

Para construir um modelo de desenvolvimento sustentável, é necessário incentivar a participação de seus cidadãos e cidadãs, promovendo a responsabilidade de todos sobre o presente e o futuro da localidade, dos territórios, tendo a gestão ambiental como vetor de planejamento democrático. Nesse sentido, o presente trabalho tem como objetivo geral o diagnóstico das condições sanitárias e ambientais do município de Montadas (PB), a partir da percepção dos moradores relacionada aos problemas de saneamento e riscos ambientais. A execução deste trabalho se fez mediante a realização de entrevistas com moradores da cidade, por meio de questionário/formulário, a cerca das questões problemáticas da temática. A análise dos dados revelou problemas no manejo e acondicionamento dos resíduos sólidos domésticos, no ambiente da residência e na via pública. Portanto, é fundamental o esclarecimento aos moradores sobre os riscos e a importância do envolvimento nas ações, de modo que torna-se indispensável a sua participação no processo de transformação da cidade no contexto sustentável, garantindo a segurança e a qualidade de vida para todos.

Palavras-chave: Gestão ambiental, condições sanitárias e ambientais, desenvolvimento sustentável.

\section{INTRODUÇÃO/OBJETIVO}

A deficiência na gestão correta de infraestrutura de saneamento pertinente ao abastecimento e tratamento de água para o consumo humano, ao esgotamento sanitário, à coleta e disposição final dos resíduos sólidos, são preocupações importantes quando falamos em sustentabilidade. Há uma insustentabilidade das relações das pessoas com a natureza e com os seus resíduos, que pode ocasionar um grande número de impactos sociais e ambientais que atingem os ecossistemas locais e a saúde da população.

Para que essas relações sejam viáveis, é necessário que haja uma educação voltada para o processo Gestão Ambiental. É neste contexto que emerge o presente projeto, buscando despertar a população para os problemas de saúde pública e ambientais, gerados pelo mau gerenciamento da qualidade dos serviços em saneamento, dentre eles o acondicionamento inadequado dos resíduos sólidos domiciliares, bem como, atingir 


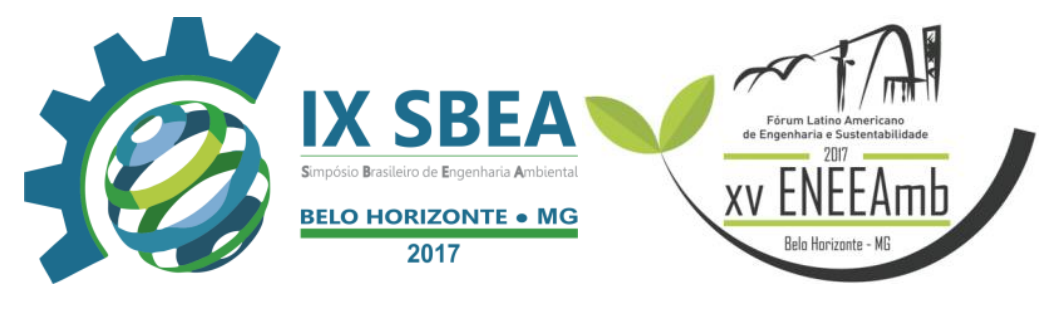

propostas concretas de mudanças de hábitos quanto aos padrões de consumo e produção dos mesmos.

O desenvolvimento deste trabalho baseia-se na aprendizagem social na participação das equipes envolvidas e da população, articulando as diferentes políticas setoriais em meio ambiente, saúde, recursos hídricos e educação, visando o fortalecimento da atuação no desenvolvimento de ações de educação ambiental.

O presente trabalho tem como objetivo geral o diagnóstico das condições sanitárias e ambientais do município de Montadas (PB), a partir da percepção dos moradores relacionada aos problemas de saneamento e riscos ambientais.

\section{METODOLOGIA}

A execução deste trabalho se fez mediante a realização de entrevistas com moradores da cidade, acerca das questões problemáticas da temática, permitindo ao entrevistado expressar suas opiniões e argumentos sobre o tema discutido.

Para tanto foram realizado um diagnóstico sobre a percepção sanitária e ambiental da população com base na aplicação de questionário/formulário, bem como através de documentário fotográfico sobre as etapas do sistema de gestão dos resíduos sólidos domésticos, em especial o seu acondicionamento domiciliar. O formulário elaborado para a pesquisa inicia-se com a identificação do entrevistado, mostrando seu perfil e sua participação na sociedade, passando gradativamente para as questões específicas ligadas ao tema do trabalho, composto por trinta questões, permitindo uma interpretação objetiva.

O trabalho foi realizado na área central da cidade de Montadas - PB, situada a 137 km da capital João Pessoa, a 750 m acima do nível do mar, tendo como coordenadas $7^{\circ} 05^{\prime} 16^{\prime \prime}$ Sul e $35^{\circ} 57^{\prime} 32^{\prime \prime}$ Oeste.

A primeira pergunta da pesquisa objetiva prende-se a identificação do entrevistado. Em seguida o morador é abordado com questões sobre seus aspectos da qualidade de vida, detalhando a característica da habitação, condições do ambiente físico e saneamento básico. Na parte de informações gerais sobre resíduos sólidos, o questionário solicita quanto a uma possível separação do resíduo nas residências, se a população tem conhecimento da diferença de Lixo Orgânico e Lixo Reciclável, se seria 


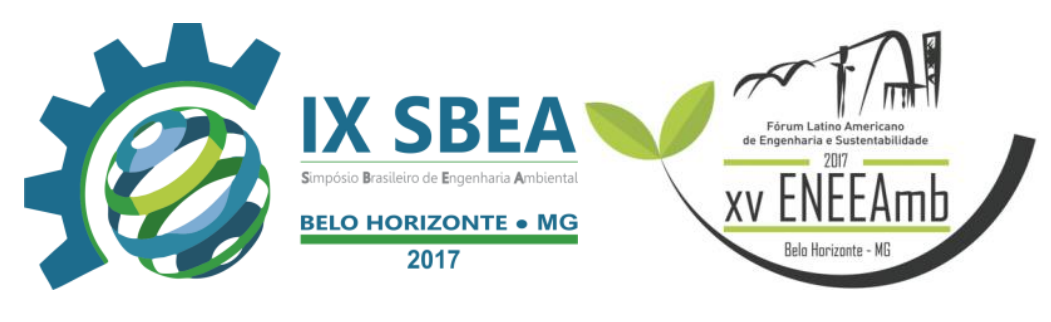

de interesse da população participar de um programa de educação visando à melhoria da forma de armazenamento e apresentação do seu resíduo para coleta pública no município.

A forma de acondicionamento e armazenamento é examinada quanto ao tipo de local é utilizado para armazenar o resíduo, se o saco utilizado para o acondicionamento, e se o seu recipiente para armazenamento seria adequado. Quanto à limpeza pública as questões abrangem a quantidade de vezes que é realizada a coleta em sua residência e a frequência com que o resíduo é recolhido no sistema regular de coleta.

O projeto visou à capacitação dos alunos e moradores, o empenho dos mesmos para lidar com o tema central do projeto que é o diagnóstico das condições sanitárias e ambientais.

\section{RESULTADOS E DISCUSSÃO}

A prefeitura é o órgão responsável pela coleta, destino final, controle e fiscalização do resíduo domiciliar, comercial e público. Compete à administração municipal recomendar a população e incentivar o uso adequado de recipientes para o acondicionamento do resíduo, como:

> Domiciliar: recipiente com tampa-sacos plásticos, contêineres de plástico, contêineres metálicos;

> Comercial: sacos plásticos, contêineres, tambores de 200 litros com identificação;

> Industrial: não perigoso- contêineres - perigoso- recipientes especiais;

> Saúde: sacos plásticos regulamentados pelas normas NBR 9.191 e 9.191 da ABNT, sustentados por suportes metálicos.

A responsabilidade do órgão municipal pela coleta e destino dos resíduos sólidos é reconhecida pela população, 90\% dos entrevistados atribuíram a prefeitura à responsabilidade pelos resíduos. 


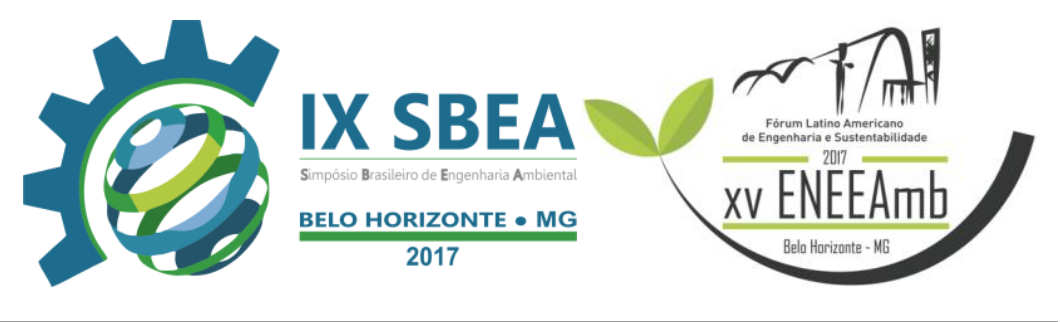

Sobre a percepção ambiental da população as informações obtidas demonstram que os munícipes não se preocupam de forma concreta com os problemas ambientais da sua comunidade, geralmente, por falta de conhecimento sobre os malefícios, o que exige por parte dos órgãos competentes o desenvolvimento de uma política ambiental atuante e de valorização dos recursos naturais.

A desinformação sobre os problemas ambientais provocados pelos resíduos domiciliares se constataram pela entrevista, 57\% não sabe a diferença entre resíduo orgânico e resíduo reciclável, 95\% nunca pensou em alguma forma de reaproveitar o resíduo produzido, $57 \%$ não sabe o que é compostagem, e $83 \%$ se quer sabe onde é depositado os resíduos produzidos, no entanto todos responderam estar satisfeito com a coleta de resíduos no município.

Os dados confirmam que a maior parte dos moradores armazenam seus resíduos em lixeira tampada com o uso de sacola plástica (Fig. 1), e cerca de 30\% armazenam em lixeira tampada sem o uso de sacola plástica, mesmo assim $83 \%$ consideraram correta a forma de acondicionamento dos resíduos domiciliares, comprovando mais uma vez, a necessidade de se investir em uma política de Educação Ambiental que sensibilize a população e os instigue aos cuidados com o meio ambiente.

Figura 1: Formas de acondicionamento dos resíduos domiciliares em Montadas-PB

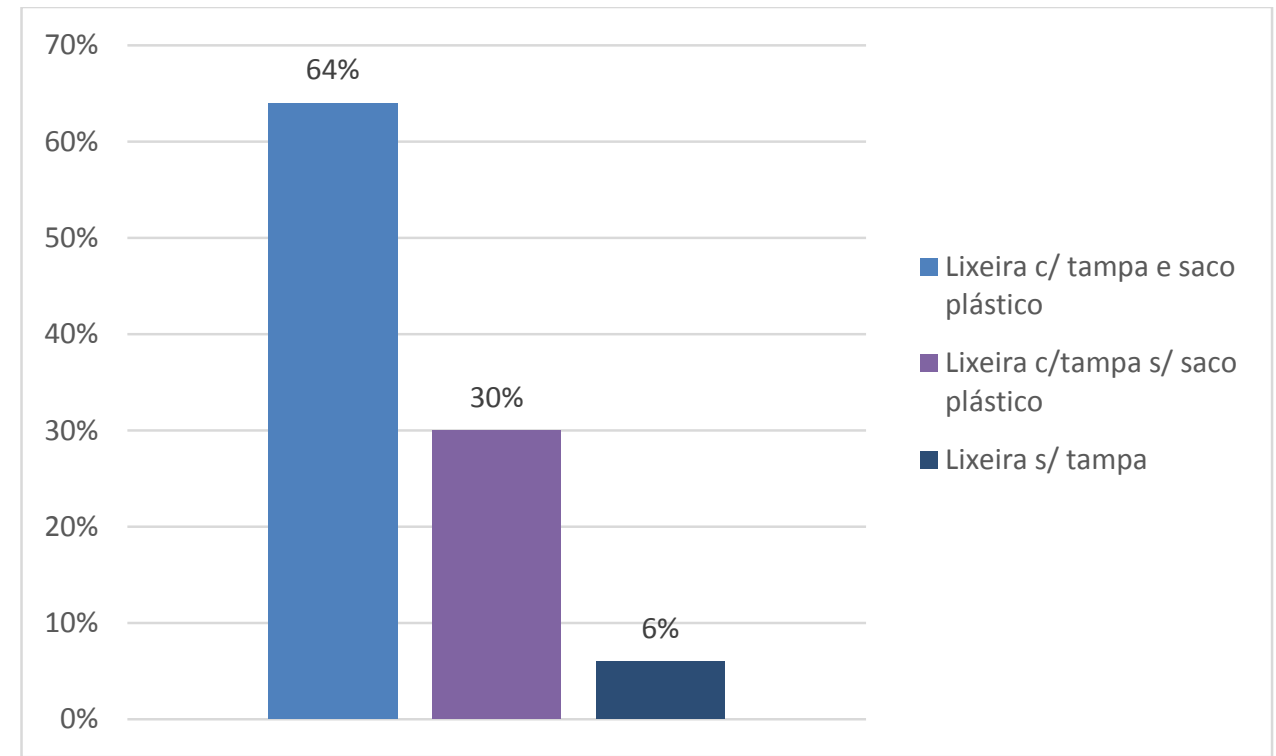




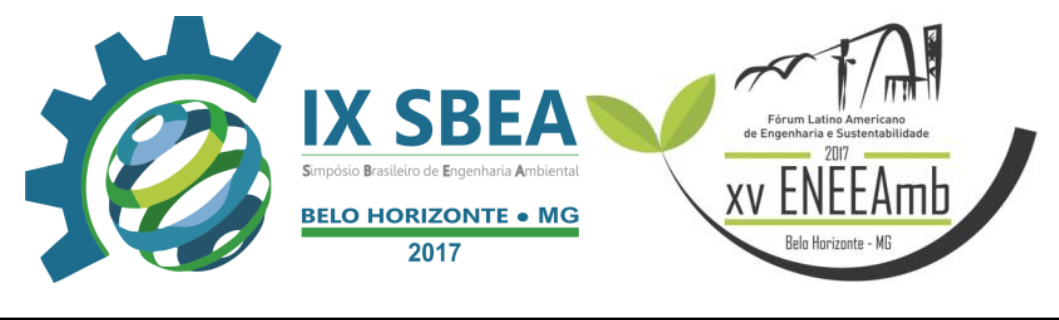

Fonte: Pesquisa/2016

A figura 2 - apresenta uma situação de acumulo de resíduo em terrenos no entroncamento entre ruas onde a coleta é realizada três vezes por semana em cada sentido (vertical e horizontal), facilitando a ação de vetores (a), a apresentação do resíduo fora do recipiente de armazenamento de resíduos sólidos em uma rua pública causando aspecto visual negativo ao ambiente (b).

Figura 2: Mostra o aspecto de sujeira deixada no local de apresentação do resíduo para coleta (a). Resíduo espalhado pela via pública, apesar do armazenamento do resíduo (b).

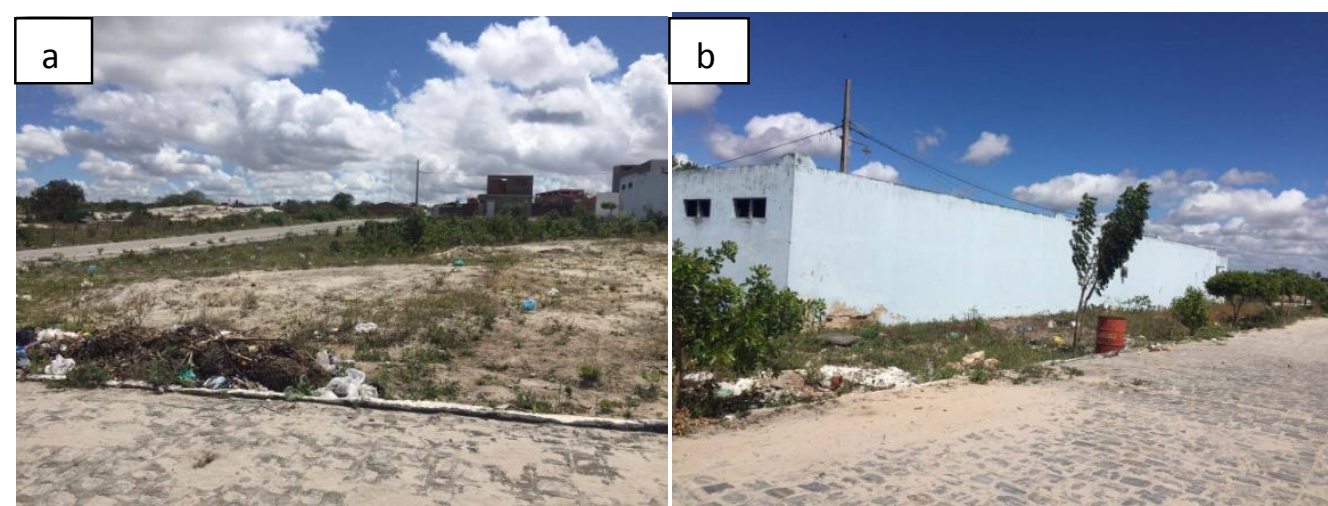

Fonte: Pesquisa/2016

O acondicionamento dos resíduos domiciliares associado à forma de armazenagem da água tem demonstrado uma situação de risco à população, já que a maior parte das famílias entrevistadas armazena água em caixa de água, tanques, baldes e latas, correspondendo a 77\% dos moradores (Fig. 3), o que demonstra no ponto de vista sanitário uma predisposição a contaminação e possibilidade de doenças diarréicas.

Apesar do alto percentual de moradias que armazenam água, que segundo o Ministério da Saúde (MS, 2013) apresentou indicadores acima da média nacional dos casos de dengue no Brasil e na condição de risco quando o índice é superior a 4,0 no grupo I de alto risco, o município de Montadasapresentou esse índice menor que a média, fazendo parte do grupo IV, que é o de municípios silenciosos em 2013 para dengue, ou seja, sem óbitos por dengue em 2013 e sem informação do IIP(Índice de Infestação Predial) no ano da pesquisa realizada pelo MS, 2013. 


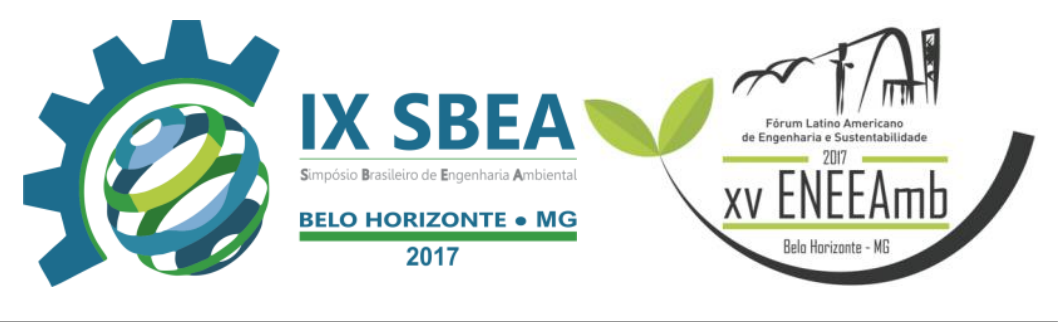

Figura 3: Locais de armazenagem de água nas residências

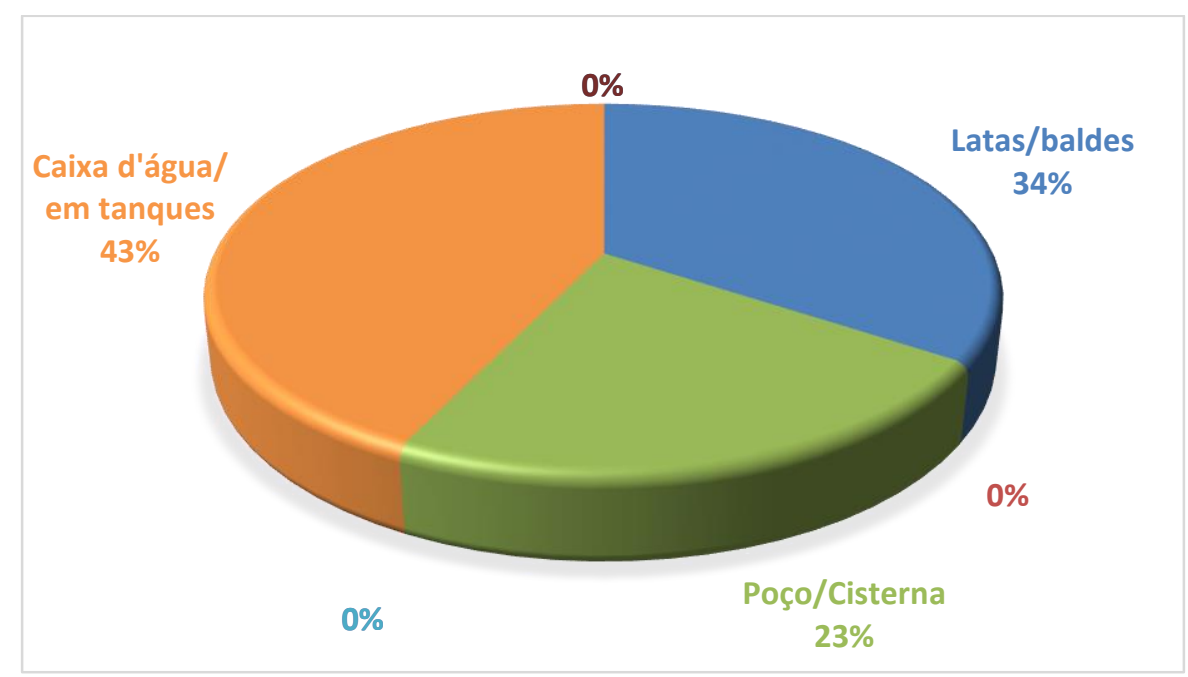

Fonte: Pesquisa/2016

A figura 4 - apresenta uma situação da realidade da cidade de Montadas do abastecimento de água realizada por caminhões-pipa e por caixa d'água geralmente localizadas em ponto centrais da cidade, como na escola Erasmo de Araújo Souza (EMEFEAS).

Figura 4: Situação do abastecimento de água da cidade de Montadas
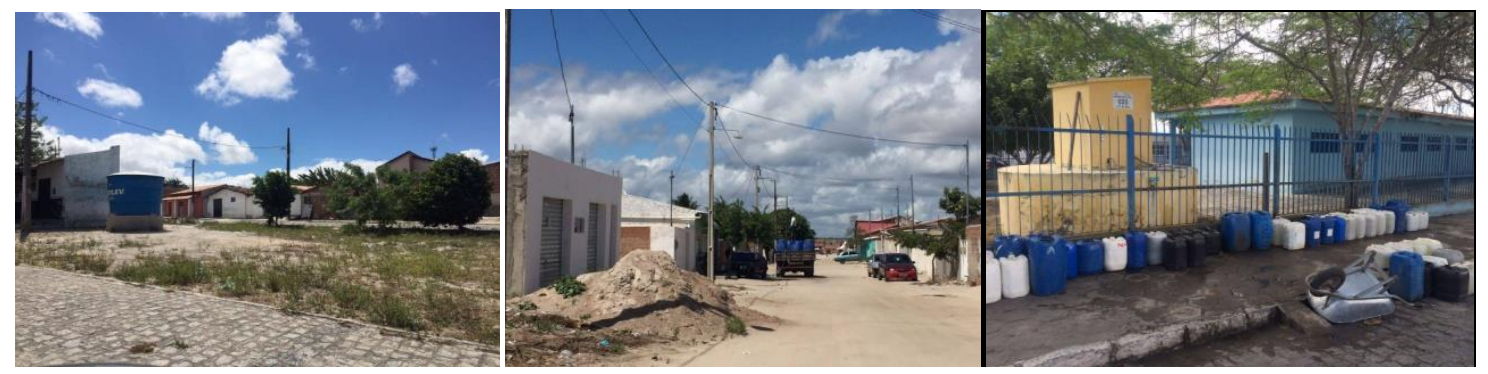

Fonte: Pesquisa/2016

Outro fator preocupante são as condições de saneamento básico, pois conforme se constatou a armazenagem de água é uma prática comum no município, já que a água encanada existente não funciona o abastecimento na rede de distribuição devido à falta de água na cidade. Quanto ao destino dessa água via esgoto $36 \%$ das moradias jogam seus 


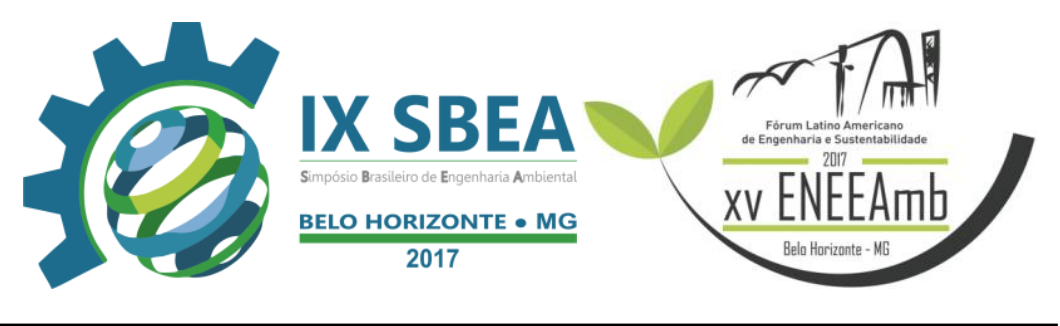

dejetos a céu aberto e $48 \%$ em fossas sépticas (Fig. 5), comprovando que na área de estudo da pesquisa não existe esgoto encanado.

O esgoto exposto atrai vetores, insetos, animais entre outros que contribuem para proliferação de doenças nos seres humanos que ali circulam. Embora $100 \%$ das residências visitadas possuam instalações sanitárias, pouco ameniza os problemas de saúde, uma vez que os dejetos destes escorrem pelas ruas e vielas a céu aberto.

Figura 5: Condições de saneamento básico das famílias entrevistadas

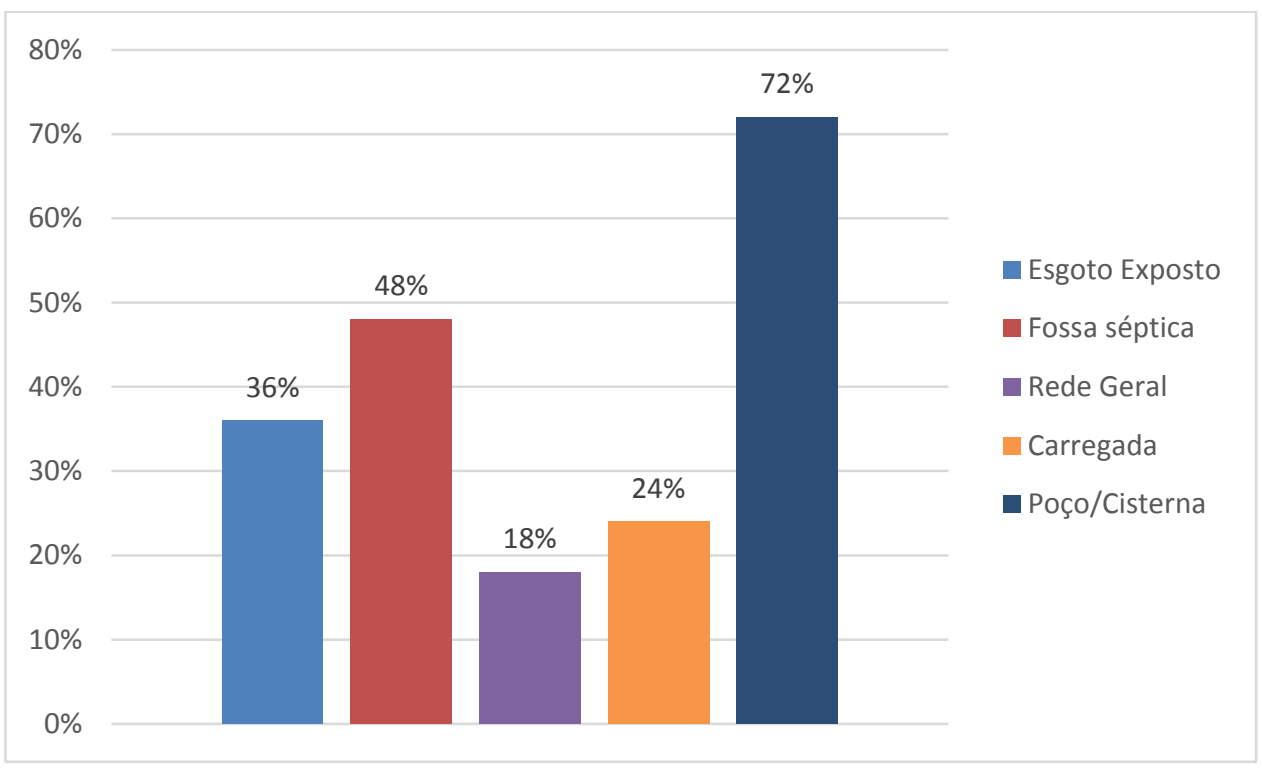

Fonte: Pesquisa/2016

\section{CONCLUSÕES/RECOMENDAÇÕES}

O projeto realizado promoveu a capacitação dos alunos orientados que vão desde a informação sobre o correto acondicionamento dos resíduos sólidos e sua adequada segregação, e técnicas de incentivos para uma Educação Ambiental efetiva, melhorando as condições sanitárias, e consequentemente a qualidade de vida da população.

Para capacitação dos alunos, houve reuniões envolvendo o grupo com orientações para formas de abordagem do tema e do público alvo e elaboração de apresentação relacionada ao tema do projeto. Além disso, elaboração de um questionário pelos alunos 


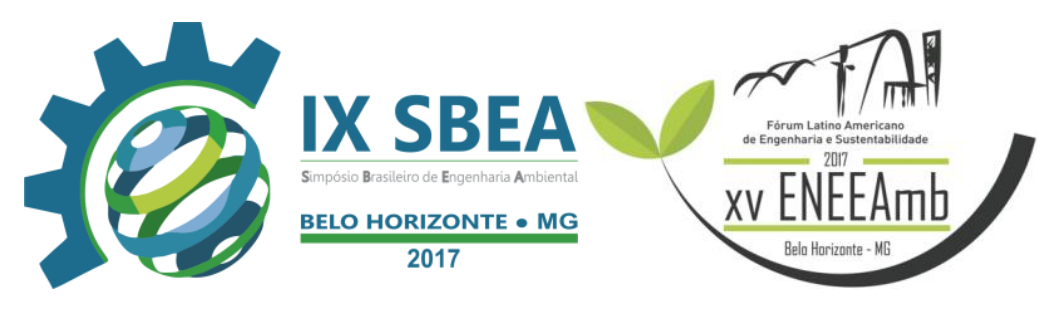

envolvidos no projeto, para ser posteriormente aplicado a uma comunidade para diagnóstico das condições sanitárias e ambientais.

A análise dos dados revelou problemas no manejo e acondicionamento dos resíduos sólidos domésticos, no ambiente da residência e na via pública. O esclarecimento aos moradores sobre os riscos e a importância do envolvimento nas ações torna-se indispensável a sua participação no processo de transformação da cidade no contexto sustentável, garantindo a segurança e a qualidade de vida para todos.

O resultado final esperado foi o diagnóstico da situação de saneamento ambiental e das condições de moradia da população, para fins de projeto futuro no qual serão elaborados planos que visarão à contribuição para uma melhor gestão ambiental do município.

\section{REFERÊNCIAS BIBLIOGRÁFICAS}

BRASIL. Política Nacional de ResíduosSólidos. Lei 12.305, de2 de agosto de 2010.

BRASIL. Diretrizes Nacionais para o Saneamento Básico. Lei 11.445, de 05 de janeiro de 2007.

Ferreira, R. S.; Costa A. F. A coleta e o acondicionamento de resíduos sólidos domésticos em Goiás-go/2012. In:Semana de Integração Acadêmica, Goiás - GO, 2012.

Reis, J. P. A.; Ferreira, O. M. Aspectos sanitários relacionados á apresentação do lixo urbano para coleta pública. Goiânia-GO, 2008.

MONTEIRO, J. H. P.Manual de Gerenciamento Integrado de Resíduos Sólidos. Rio de Janeiro: IBAM, 2001.

VARGAS, A. C.; STANGE C. E. B. - Educação Sanitária: Contribuições ao aprendizado em conteúdos de Ciências Biológicas na Educação Básica, Ensino Médio2010 Disponível

em: <http://www.diaadiaeducacao.pr.gov.br/portals/pde/arquivos/2075-8.pdf> Acesso em: 29/10/2012. 


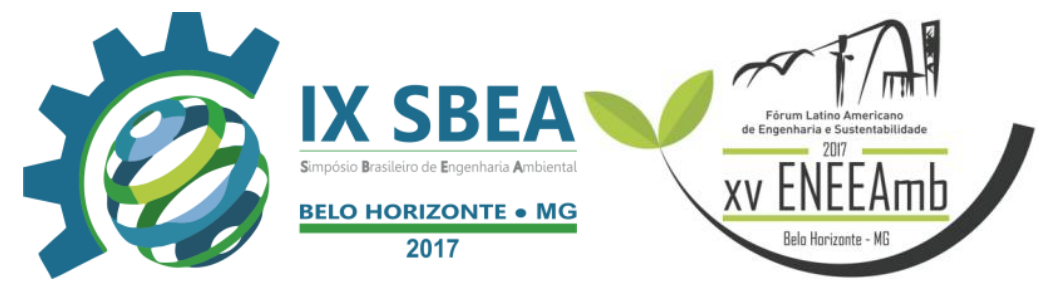

VELASCO, Sirio L. Perfil da Lei de Política Nacional de Educação Sanitária e Ambiental.In: Revista Eletrônica do Mestrado em Educação Sanitária e Ambiental FURG. Vol. 2, Jan. - Mar/2000. 07 págs. 